\title{
Nitrogen-doped graphene/CdS hollow spheres nanocomposite with enhanced photocatalytic performance
}

\author{
Qian Mi, Daiquan Chen, Juncheng Hu*, Zhengxi Huang\#, Jinlin Li \$ \\ Key Laboratory of Catalysis and Materials Science of the State Ethnic Affairs Commission \& Ministry of Education, South-Central University for \\ Nationalities, Wuhan 430074, Hubei, China
}

\section{A R T I C L E I N F O}

\section{Article history:}

Received 4 June 2013

Accepted 21 June 2013

Published 20 November 2013

Keywords:

Nitrogen-doped graphene

Cadmium sulfide

Hollow spheres

Photocatalysis

\begin{abstract}
A B S T R A C T
A novel N-doped graphene/CdS hollow sphere nanocomposite photocatalyst was synthesized by a simple, template-free one-pot method. The samples were characterized by X-ray diffraction, transmission electron microscopy, Fourier transform infrared spectroscopy, ultraviolet-visible diffuse reflectance spectroscopy, $\mathrm{N}_{2}$ adsorption-desorption, photoluminescence spectroscopy, and X-ray photoelectron spectroscopy. Photocatalytic degradations of methylene blue and salicylic acid were carried out to evaluate the photocatalytic activity of the nanocomposites under visible light irradiation. The N-graphene/CdS nanocomposites exhibited excellent stability and high photocatalytic activity, exceeding those of graphene oxide/CdS hollow sphere nanocomposites and pure CdS hollow spheres. This excellent photocatalytic activity of the nanocomposite was due to N-graphene acting as an excellent electron acceptor and transporter, thus reducing charge carrier recombination. It was also found that $\cdot \mathrm{OH}$ acted as the main reactive species in the degradation of methylene blue under visible-light irradiation.
\end{abstract}

(C) 2013, Dalian Institute of Chemical Physics, Chinese Academy of Sciences. Published by Elsevier B.V. All rights reserved.

\section{Introduction}

In view of increasingly serious energy and environmental problems, many researchers have studied photocatalytic materials to alleviate the deterioration of the natural environment by toxic pollutants and the exhaustion of energy resources by splitting water using light energy to produce hydrogen [1,2]. As a green technology, photocatalysis has attracted increasing interest because it can be widely applied as an economically and ecologically safe option to solve energy and pollution problems [3]. In particular, photocatalytic degradation of organic dyes using semiconductor photocatalysts is gaining growing research interest for water purification. Among all the photocatalytic materials previously reported, CdS is one of the metal sulfide materials most studied as a photochemical catalyst because of its unique photochemical and photophysical properties, such as an intrinsic narrow band, high efficiency, photochemical stability, and low cost for wastewater treatment [4-7].

However, there are still two main challenges to be overcome. The first is the low separation efficiency of photo-generated electrons and holes and the fact that CdS is easily corroded through oxidization by the photogenerated holes [8]. Secondly, CdS tends to aggregate to form larger particles, which results in a reduced surface area $[9,10]$. The development of highly efficient and robust visible-light responsive photocata-

\footnotetext{
*Corresponding author. Tel: +86-27-67841302; Fax:+86-27-67841302; E-mail: junchenghuhu@hotmail.com

\# Corresponding author. Tel: +86-27-67841302; Fax: +86-27-67842752; E-mail: zxhuang2005@126.com

\$Corresponding author. Tel: +86-27-67843016; Fax: +86-27-67842752; E-mail: jinlinli@aliyun.com

This work was supported by the National Basic Research Program of China (2011CB211704), the National Natural Science Foundation of China (20803096, 21073238), and the Natural Science Foundation of Hubei Province for Distinguished Young Investigator (2010CDA082).

DOI: 10.1016/S1872-2067(12)60641-X | http://www.sciencedirect.com/science/journal/18722067 | Chin. J. Catal., Vol. 34, No. 11, November 2013
} 
lysts is of great importance and a challenge for their industrial application. To overcome these shortcomings, attempts have recently been made to improve the stability of the photocatalytic performance of CdS by controlling its bandgap and absorption properties using metal ion dopants such as $\mathrm{Mn}, \mathrm{Co}, \mathrm{Fe}$, and $\mathrm{Ni}$, or by incorporating metal sulfide nanoparticles into interlayer photocatalysts $[11,12]$.

Since its discovery in 2004 by Geim and co-workers [13], graphene has sparked overwhelming research efforts because of its extraordinary mechanical, thermal, chemical, and optical properties and potential applications [14-16]. However, a graphene-metal interface has an existence or absence of the energy gap in the energy dispersion for the graphene states around the Dirac point [17]. Hetero-atom doping of graphene can dramatically alter its electrical properties and modulate its band structure [18-22]. Doping with nitrogen, boron, sulfur, or phosphorus has been shown to effectively modify the physical, chemical, and electronic properties of carbon materials [23]. Especially, N-graphene has some properties that differ from those of pristine graphene. On one hand, the spin density and charge distribution of carbon atoms are influenced by neighboring nitrogen dopant atoms, which induces an "activation region" on the graphene surface [24]. On the other hand, nitrogen doping of monolayer graphene causes its Fermi level to shift above the Dirac point [25], and the density of states near the Fermi level is suppressed; thus, the band gap between the conduction band and the valence band is opened [26,27]. Moreover, N-graphene can also be used as an electrode material for lithium ion batteries, as a catalyst for oxygen reduction reactions, and in chemical sensor or biosensor devices [28,29].

However, there are few literature reports in which $\mathrm{N}$-graphene has been combined with metal sulfide as a photocatalyst, and all of those concern CdS particles supported on $\mathrm{N}$-graphene sheets. Thus, we herein report for the first time CdS hollow spheres supported on the surface of N-graphene nanosheets (N-graphene/CdS HSNs), and present a simple, template-free one-pot method for their fabrication. The prepared samples were found to exhibit higher photocatalytic activity than that of graphene oxide (GO)/CdS HSNs and sole CdS hollow spheres during photocatalytic degradation experiments. The results indicated that $\mathrm{N}$-graphene acts as an electron transfer channel to reduce photogenerated electron-hole recombination, resulting in an enhancement of the photoconversion efficiency of the CdS photocatalyst. Rapid hole transfer and high electron-hole pair separation efficiency led to the observed dramatically enhanced photoactivity and inhibited photocorrosion. Furthermore, we also studied the roles of different reactive species and discuss a probable charge transfer mechanism.

\section{Experimental}

\subsection{Sample preparation}

\subsubsection{Synthesis of N-graphene}

GO was prepared from natural graphite powder (purchased from Alfa-Aesar) using the modified Hummers method [30].
$\mathrm{N}$-graphene was synthesized as follows [31]. In a typical synthesis, $120 \mathrm{mg}$ GO was added to $100 \mathrm{~mL}$ distilled water with ultrasonication for $30 \mathrm{~min}$, resulting in a homogeneous dispersion. The $10 \mathrm{~mL} 50 \%$ cyanamide $\left(\mathrm{NH}_{2} \mathrm{CN}\right.$, from Aladdin) was added to the mixture under stirring, and the mixed solution was then heated at $90{ }^{\circ} \mathrm{C}$ until dryness. The obtained products were subsequently transferred to a furnace, heated at $450{ }^{\circ} \mathrm{C}$ for $1 \mathrm{~h}$, further annealed at $900{ }^{\circ} \mathrm{C}$ for $2 \mathrm{~h}$, and then allowed to cool.

\subsubsection{Synthesis of N-graphene/CdS HSNs}

In a typical synthesis, $16 \mathrm{mg} \mathrm{N}$-graphene, $5.5 \mathrm{mmol}$ reduced L-glutathione (GSH, from Aladdin) and an appropriate molar ratio of cadmium nitrate tetrahydrate $\left(\mathrm{Cd}\left(\mathrm{NO}_{3}\right)_{2} \cdot 4 \mathrm{H}_{2} \mathrm{O}\right.$, from Aladdin) was dissolved in $230 \mathrm{~mL}$ distilled water. After being continuously stirred for $24 \mathrm{~h}$, the resulting transparent solution was transferred into an autoclave with a quartz liner. The autoclave was purged with $\mathrm{N}_{2}$ three times, and then a pressure of 10 bar nitrogen was applied. The solution was heated to $200{ }^{\circ} \mathrm{C}$ and held for $24 \mathrm{~h}$. The precipitates from the mixture were allowed to cool to room temperature, washed several times with ethanol, and then dried in an oven at $60{ }^{\circ} \mathrm{C}$ overnight to obtain the final product.

\subsection{Sample characterization}

The crystalline structure of the catalysts was studied by powder X-ray diffraction (XRD) using a scanning rate of $0.05^{\circ} / \mathrm{s}$ within a $2 \theta$ range of $10^{\circ}-80^{\circ}$ (Bruker D8 Advance; $\mathrm{Cu} K_{\alpha}=$ $1.5404 \AA$ ). Transmission electron microscopy (TEM) and highresolution transmission electron microscopy (HRTEM) analyses were carried out using a Tecnai G20 microscope operated at an accelerating voltage of $200 \mathrm{kV}$. Ultraviolet-visible (UV-vis) diffuse reflectance spectra (DRS) were collected using a Shimadzu UV-2450 spectrophotometer from 200 to $800 \mathrm{~nm}$ using $\mathrm{BaSO}_{4}$ as a background reference. The BET specific surface area of the samples was evaluated on the basis of $\mathrm{N}_{2}$ adsorption isotherms using a Micromeritics ASAP 2020 gas adsorption apparatus (USA). Fourier transform infrared (FT-IR) spectra were collected using a Nicolet Nexus 6700 spectrophotometer from 400 to $4000 \mathrm{~cm}^{-1}$. The photoluminescence (PL) spectra of the samples were recorded with a PE LS55 spectro fluorophotometer. X-ray photoelectron spectroscopy (XPS) was carried out using a VG Multilab 2000 instrument (VG Inc.)

\subsection{Photocatalytic activity measurements}

Photocatalytic degradation experiments were performed under atmosphere, with 50 mg of catalyst and methylene blue (MB, from Sinopharm Chemical Reagent Co. Ltd., Shanghai, China; $50 \mathrm{~mL}, 2.5 \times 10^{-5} \mathrm{~mol} / \mathrm{L}$ ) or salicylic acid (form Sinopharm, $50 \mathrm{~mL}, 20 \mathrm{mg} / \mathrm{L}$ ) placed in a Pyrex glass cell in an optical system comprising a $350 \mathrm{~W}$ Xe lamp with a $420 \mathrm{~nm}$ cut-off filter. Prior to irradiation, the suspensions were magnetically stirred in the dark for $4 \mathrm{~h}$ to ensure the establishment of an adsorption/desorption equilibrium between the organic species and the catalyst. At given irradiation time intervals, 4 
$\mathrm{mL}$ solution was collected, centrifuged, and then filtered through a Millipore filter (pore size $0.45 \mu \mathrm{m}$ ) to remove the catalyst particulates. Finally, the reaction vessel was exposed to the visible-light irradiation, and the same sample collection steps were carried out. For comparison, we also tested the photocatalytic activities of GO/CdS HSNs, CdS hollow spheres, and Degussa P25 under the same experimental conditions.

\subsection{Analysis of reactive species}

The production of $\cdot \mathrm{OH}$ on the surface of visible light illuminated N-graphene/CdS HSNs was detected by a PL method, in which coumarin was used as a probe molecule [32]. In the detection experiment, $50 \mathrm{mg}$ catalyst powder was added to an aqueous coumarin solution (50 mL, $\left.5 \times 10^{-4} \mathrm{~mol} / \mathrm{L}\right)$ and the resulting suspension was magnetically stirred in dark for $4 \mathrm{~h}$ prior to irradiation. The mixture was then irradiated under visible light ( $>420 \mathrm{~nm}$ ), and samples were withdrawn at regular intervals and centrifuged to separate out the solid particles before analysis. The reaction solution was filtered to measure increases in the PL intensity at around $445 \mathrm{~nm}$ excited by 332 nm light.

The process used to examine the reactive species was similar to that used in the photocatalytic activity measurements. A quantity of scavenger was introduced into the MB solution prior to addition of the catalyst, benzoquinone (as a scavenger for superoxide radical species), and isopropanol (as a scavenger for hydroxyl radicals). The scavenger concentration was set at $0.2 \mathrm{mmol} / \mathrm{L}$ based on previous work [33].

\section{Results and discussion}

\subsection{Microstructure characterizations}

The XRD patterns of as-prepared GO and N-graphene are shown in Fig. 1. A sharp (001) diffraction peak at $10.4^{\circ}$ was attributed to GO [34], and disappearance of the characteristic (001) diffraction of GO at $26.3^{\circ}$ illustrated that oxidation took place, resulting in the formation of a highly ordered, lamellar

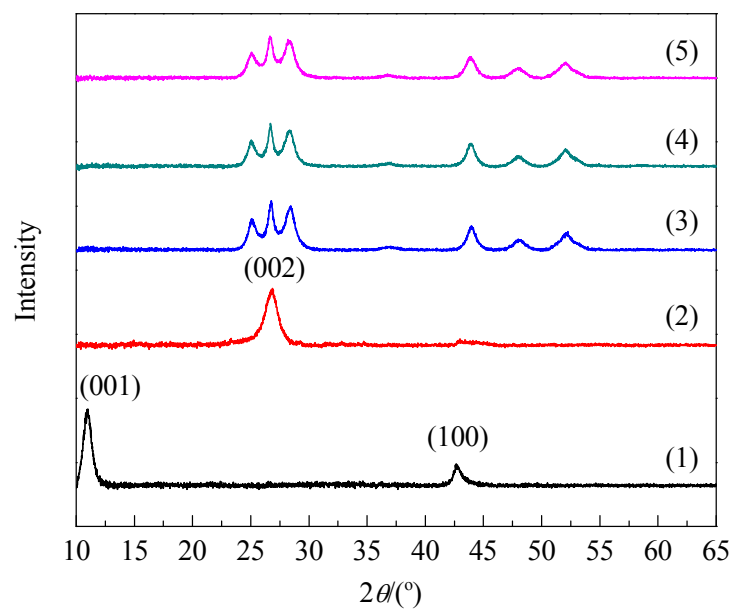

Fig. 1. XRD patterns of GO (1), N-graphene (2), CdS hollow spheres (3), GO/CdS HSNs (4), and N-graphene/CdS HSNs (5). structure. The XRD peak at $26.3^{\circ}$, corresponding to $0.34 \mathrm{~nm}$, indicates that the $\mathrm{GO}$ was reduced to graphene by $\mathrm{N}$ doping [35]. The XRD patterns of CdS, GO/CdS HSNs, and N-graphene/CdS HSNs indicated that all samples were composed of a hexagonal CdS phase according to JCPDS No. 41-1049. However, no $\mathrm{N}$-graphene diffraction peaks were detected in the $\mathrm{N}$ graphene/CdS HSNs pattern. This may be ascribed to two probable reasons. One is that due to low $\mathrm{N}$-graphene content, the main characteristic peak of $\mathrm{N}$-graphene at $26.3^{\circ}$ might be shielded by the main peak of $\mathrm{CdS}$ at $26.5^{\circ}$, and the other may be that the layer-stacking regularity disappeared after redox of the graphite [36].

The morphology and structure of the as-synthesized samples were investigated using TEM. Figure 2(a) shows that the $\mathrm{N}$-graphene had a sheet-like morphology with a clear, smooth surface. The CdS spheres were found to range from 200 to 300 nm (Fig. 2(b)), but were not uniform in size after loading onto the N-graphene. It can be clearly seen from Fig. 2(c) that the basal plane $\mathrm{N}$-graphene nanosheet was partially bridged with CdS hollow spheres. HRTEM was carried out to characterize the $\mathrm{N}$-graphene/CdS HSNs in more detail. As shown in Fig. 2(d), the interlayer distance of the $\mathrm{N}$-graphene estimated from the HRTEM image was about $0.34 \mathrm{~nm}$, which corresponds to the (002) planes. Meanwhile, the lattice spacing of $0.35 \mathrm{~nm}$ corresponds to the (002) planes of hexagonal CdS. These results are consistent with the XRD analysis.

FT-IR was used to investigate the functional groups of the as-synthesized samples. As shown in Fig. 3, the peaks at 3425-3454 and 1629-1676 $\mathrm{cm}^{-1}$ were assigned to the $\mathrm{O}-\mathrm{H}$ stretching vibration and the adsorbed $\mathrm{H}_{2} \mathrm{O}$ bending vibration, respectively [37]. The peak at $1389 \mathrm{~cm}^{-1}$ was attributed to the $\mathrm{C}-\mathrm{O}-\mathrm{H}$ deformation vibration, and that at $1720 \mathrm{~cm}^{-1}$ to $\mathrm{C}=\mathrm{O}$ stretching vibrations from carbonyl and carboxylic groups. The $\mathrm{C}=0$ peak at $1720 \mathrm{~cm}^{-1}$ disappeared after the nitrogen doping,

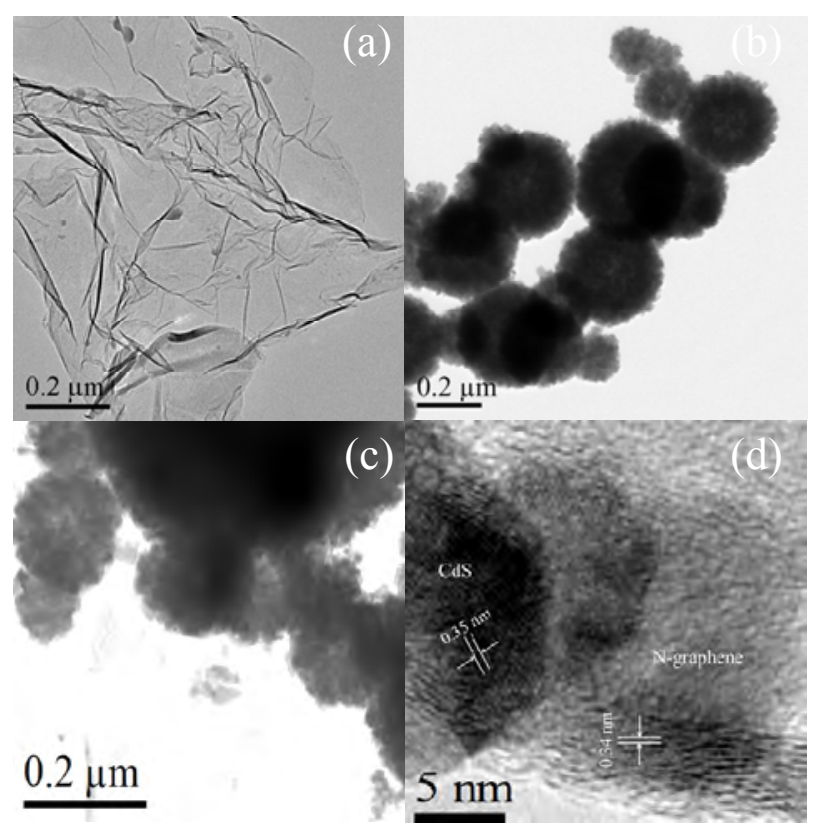

Fig. 2. TEM images of N-graphene (a), CdS hollow spheres (b), and $\mathrm{N}$-graphene/CdS HSNs (c), and HRTEM of N-graphene/CdS HSNs (d). 


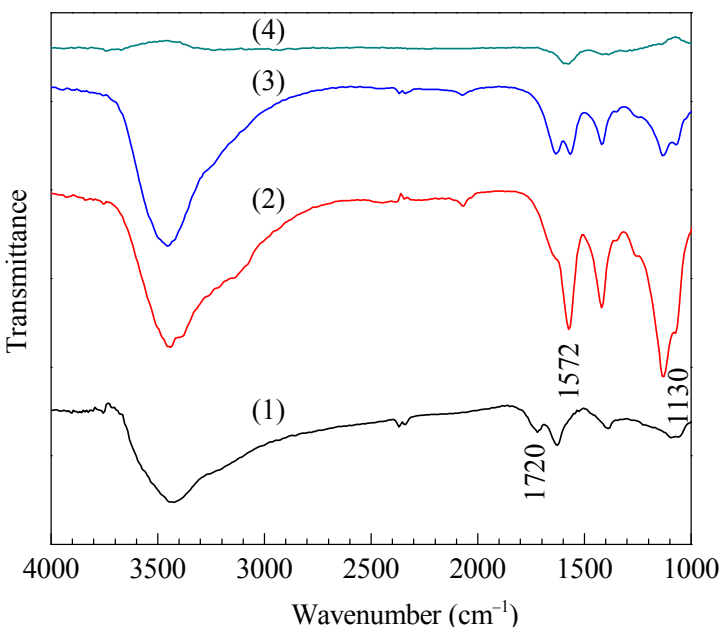

Fig. 3. FT-IR spectra of GO (1), N-graphene (2), N-graphene/CdS HSNs (3), and CdS hollow spheres (4).

indicating the reduction of $\mathrm{GO}$, and the new peaks at 1572 and $1130 \mathrm{~cm}^{-1}$ were assignable to $\mathrm{C}=\mathrm{N}$ and $\mathrm{C}-\mathrm{N}$ stretching vibrations. These results further indicate that the GO was reduced to graphene and doped with nitrogen simultaneously. However, due to the overlap of $\mathrm{C}=\mathrm{C}$ and $\mathrm{C}=\mathrm{N}$ peaks and the relatively low ratio of $\mathrm{N}$ to $\mathrm{C}$ atoms, it is difficult to prove the existence of $\mathrm{C}=\mathrm{N}$ by FT-IR [38].

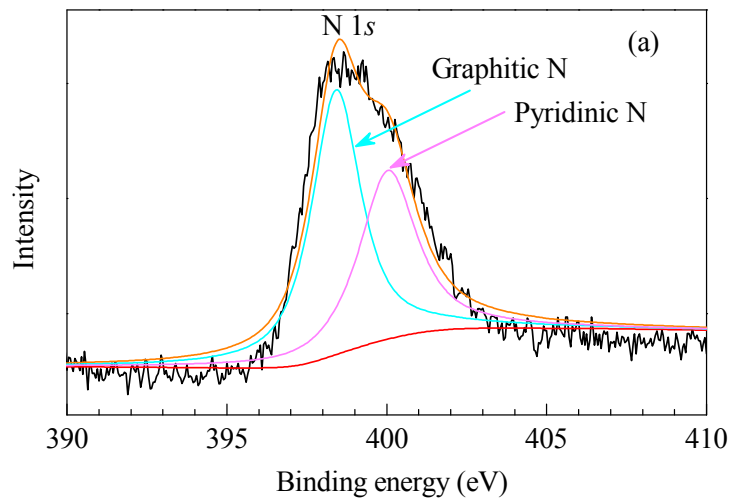

Therefore, XPS studies were carried out to confirm the successful doping of graphene with $\mathrm{N}$. The survey scan spectrum showed the presence of the principal C $1 s, 01 s$, and $\mathrm{N} 1 s$ core levels, with no evidence of impurities (Fig. 4(a)) [39]. The N $1 s$ core level peak could be resolved into two components centered at 398.4 and $400.4 \mathrm{eV}$, which are assigned to pyridinic and graphitic N species (Fig. 4(b)) [40,41]. The XPS analysis also revealed that the atomic percentage of $\mathrm{N}$ in the as-obtained $\mathrm{N}$-doped graphene was $8.74 \%$. Based on the above experimental results, it can be concluded that the GO was reduced to graphene, which was simultaneously doped with $\mathrm{N}$, and that the CdS hollow spheres were successfully loaded onto the $\mathrm{N}$-graphene.

UV-Vis DRS spectra were measured to determine the optical properties of the samples. The direct band gap values of the $\mathrm{CdS}$ and GO/CdS hollow sphere samples were estimated from the $(A h v)^{2}$ versus photon energy $(h v)$ plot as shown in Fig. 5 (b). The band gap of the N-graphene/CdS HSNs was estimated to be $2.31 \mathrm{eV}$, which is lower than that of the GO/CdS HSNs $(2.34 \mathrm{eV})$ and the CdS hollow spheres (2.39 eV). This result indicates a band gap narrowing of the CdS owing to the introduction of $\mathrm{N}$-graphene into the matrix of $\mathrm{N}$-graphene/CdS HSNs. In contrast to the spectra of the pure CdS and GO/CdS, wide background absorption was found in the visible light region for the N-graphene/CdS HSNs. This was attributable to the presence of $\mathrm{N}$ in the $\mathrm{N}$-graphene/CdS HSNs, reducing the re-

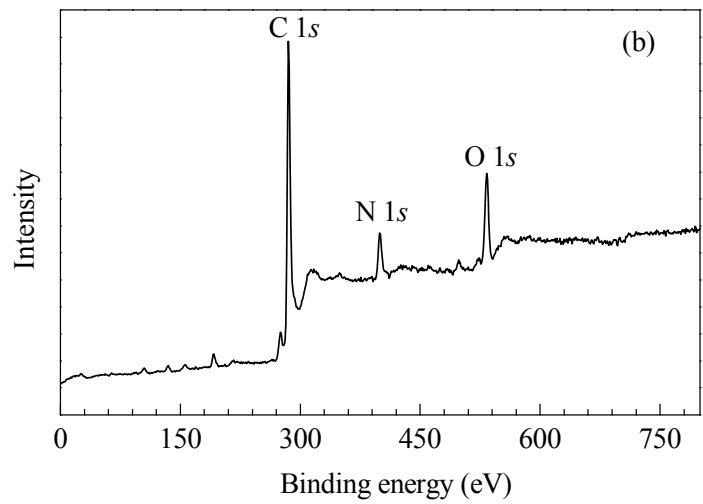

Fig. 4. XPS spectra of the N-graphene (a) and XPS N 1s spectrum of the N-graphene (b).
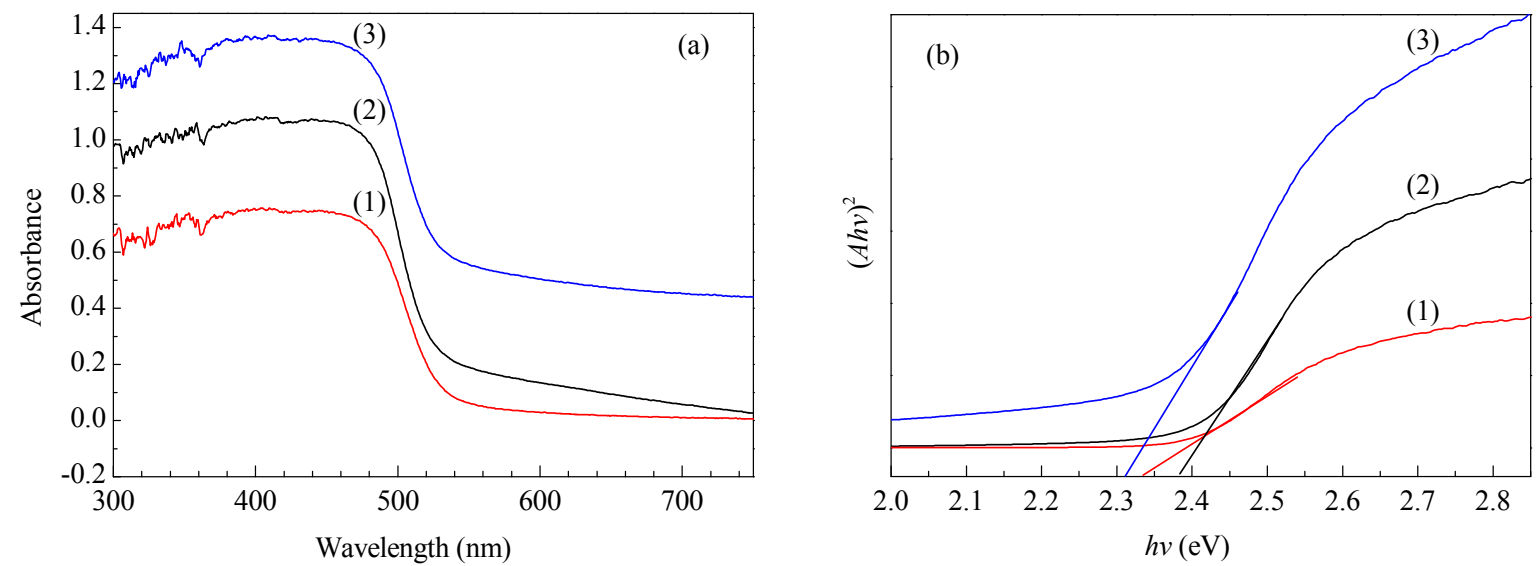

Fig. 5. (a) UV-Vis DRS spectra of N-graphene/CdS HSNs (1), CdS hollow spheres (2), and GO/CdS HSNs (3). (b) Band gaps evaluated from plots of $(A h v)^{2}$ versus photon energy $(h v)$. 


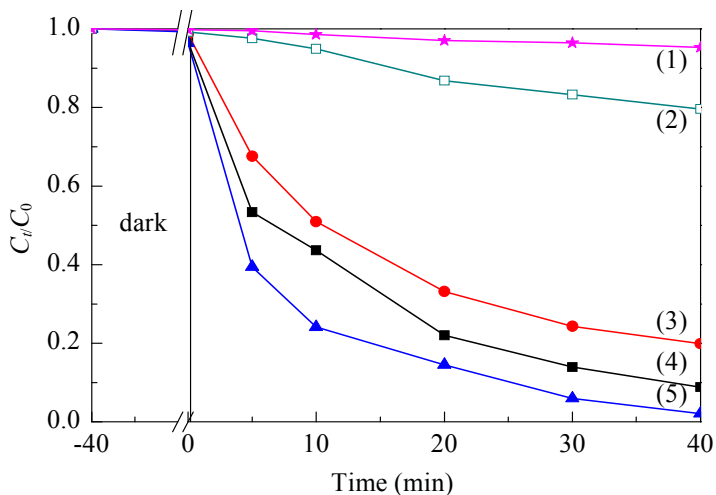

Fig. 6. Photocatalytic degradation of MB by blank (1), P25 (2), CdS hollow spheres (3), GO/CdS HSNs (4), and N-graphene/CdS HSNs (5) under visible light irradiation.

flection of light [42].

\subsection{Photocatalytic performance}

To compare the photocatalytic activities of pure CdS, P25, and the GO/CdS HSNs over time, a series of photodegradation experiments were carried out using MB as a model pollutant under simulated sunlight. While MB may absorb light itself, the resulting self-degradation is negligible when compared with the degradation catalyzed by a photocatalyst [43]. The evolution of MB photodegradation using the different photocatalysts is shown in Fig. 6. At 30 min the MB degradation percentage with pure CdS was about $75 \%$, that with P25 was only $17 \%$, and that with the GO/CdS HSNs was about 86\%. When $\mathrm{N}$-graphene was introduced to the CdS, the degradation percentage reached about $94 \%$ within the same time period. It was thus observed that the N-graphene/CdS HSNs exhibited better photocatalytic performance than GO/CdS HSNs, pure CdS, and P25.

To eliminate the influence of photosensitization, we further studied the degradation of salicylic acid. As can be seen from Fig. 7, the salicylic acid was almost completely decomposed over $\mathrm{N}$-graphene/CdS HSNs after $4 \mathrm{~h}$, while the degradation over GO/CdS HSNs was about $80 \%$ and that over CdS was only $76 \%$ after the same time. These results indicate that the multiple light reflections in the CdS hollow chamber and the effective charge separation by $\mathrm{N}$-graphene contributed to the excellent dye removal performance.

Instability has been a problem for CdS-based photocatalysts because of the possible photocorrosion of CdS in aqueous media [44]. Thus, we examined the durability of N-graphene/CdS HSNs by MB degradation for five recycles. As shown in Fig. 8, it was found that the activity did not decrease significantly; degradation remained at $90 \%$ even after five uses. The corresponding XRD patterns in Fig. 9 showed no notable differences before and after the photocatalytic recycles, indicating that the $\mathrm{N}$-graphene/CdS HSNs were photostable during the degradation of MB.

To further understand the higher photocatalytic activity of $\mathrm{N}$-graphene/CdS HSNs for photodegradation of MB than that of pure CdS and GO/CdS HSNs, several additional experiments

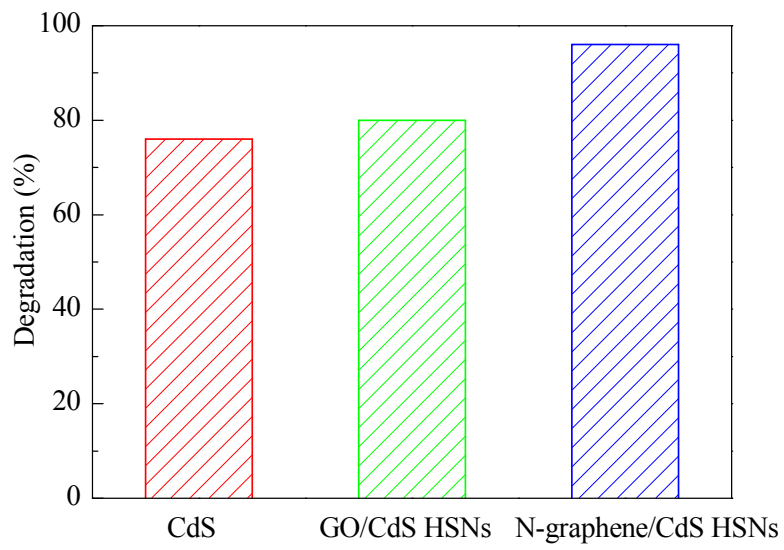

Fig. 7. Comparison of the photocatalytic activity of CdS, GO/CdS HSNs, and N-graphene/CdS HSNs for the photodegradation of salicylic acid.

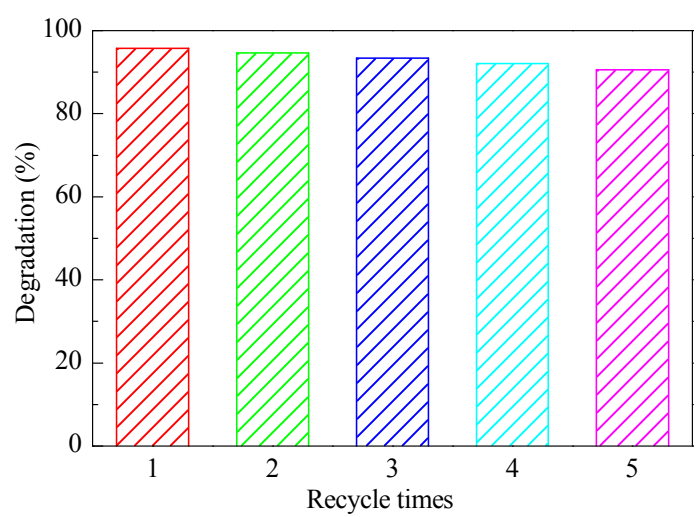

Fig. 8. Degradation percentage of $M B$ in the presence of N-graphene/ CdS HSNs $(50 \mathrm{mg})$ under visible-light $(\lambda>420 \mathrm{~nm}$ ) irradiation for 40 min.

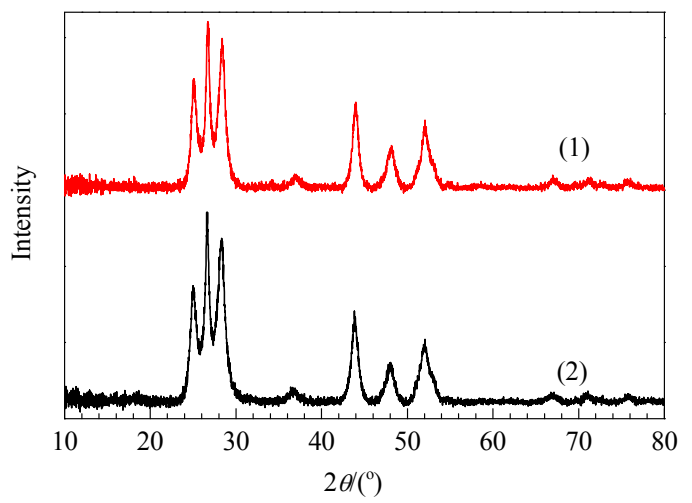

Fig. 9. XRD patterns of the fresh (1) and used five times (2) N-graphene/CdS HSNs catalyst.

were carried out. The result showed that no obvious difference in the specific surface area for these samples: the pure CdS sample had a slightly lower surface area $\left(21.8 \mathrm{~m}^{2} / \mathrm{g}\right)$ than GO/CdS HSNs (27.5 $\mathrm{m}^{2} / \mathrm{g}$ ) and N-graphene/CdS HSNs (25.1 $\mathrm{m}^{2} / \mathrm{g}$ ). This indicated that the specific surface area was not a key factor affecting the photocatalytic activity of the $\mathrm{N}$ graphene/CdS HSNs.

The prolonged lifetime of the photogenerated charge carriers was confirmed by PL spectroscopy. As shown in Fig. 10, under an excitation wavelength of $350 \mathrm{~nm}$, the PL intensity 


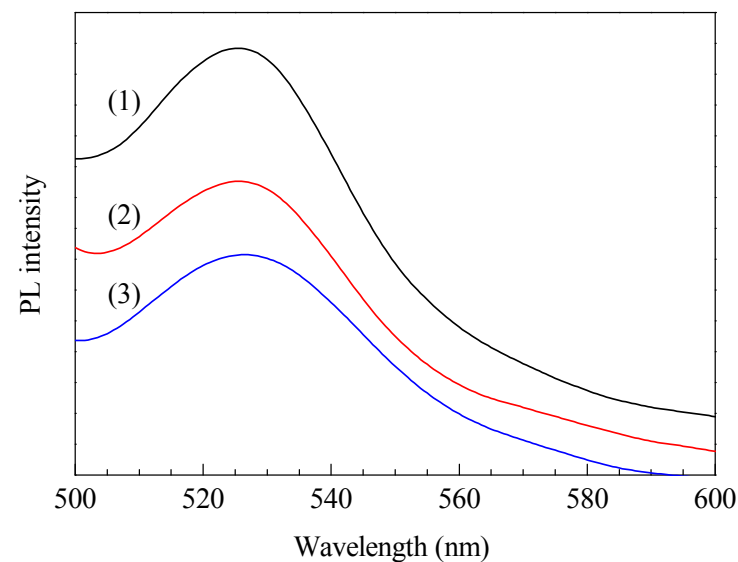

Fig. 10. PL spectra of CdS hollow spheres (1), GO/CdS HSNs (2), and N-graphene/CdS HSNs (3).

obtained over N-graphene/CdS HSNs was much weaker than that for the GO/CdS HSNs and CdS hollow spheres. This indicates a longer lifetime of photogenerated charge carriers in the N-graphene/CdS HSNs. Generally, a low electron and hole recombination rate is often associated with high photocatalytic activity [45]. The enhancement of the photocatalytic performance should be ascribed to the decreased recombination of electron-hole pairs and the increased light absorption intensity of the nanocomposites in the presence of N-graphene.

\subsection{Possible reaction mechanism for photocatalytic degradation of $M B$}

To further understand the role of photogenerated radical species on the photodegradation of MB over the N-graphene/ CdS HSNs, we detected $\cdot \mathrm{OH}$ radicals using coumarin as a probe molecule. In brief, if $\cdot \mathrm{OH}$ radicals exist in the reaction system, they can react with coumarin to form 7-hydroxycoumarin (7HC) (umbelliferone) [46]. Through the experiment for the suspension containing photocatalysts and an aqueous solution of coumarin, as shown in Fig. 11, an increase in the PL intensity at $445 \mathrm{~nm}$ excited by $332 \mathrm{~nm}$ light can be observed, confirming the generation of $\cdot \mathrm{OH}$ radicals. Quenchers were used to scavenge the relevant reactive species and thereby further evaluate their role. A comparison experiment was performed without quenchers under identical conditions. The main active species is usually different among different photocatalysts due to differences in their band structure or phase composition. Therefore, different scavengers were introduced during photocatalytic MB degradation as probes to determine the reactive species. Isopropanol and benzoquinone were used to capture $\bullet \mathrm{OH}$ and $\bullet_{2}{ }^{-}$, respectively. As shown in Fig. 12, it was found that addition of benzoquinone had no obvious effect on the photocatalytic activity, while the addition of isopropanol significantly decreased the photocatalytic activity. This suggests that $\cdot \mathrm{OH}$ may play a more important role than ${ }^{\circ} \mathrm{O}_{2}$ - for the photocatalytic degradation of MB. This result was also verified by the coumarin probing measurement (Fig. 11).

Based on the above discussion, a tentative reaction

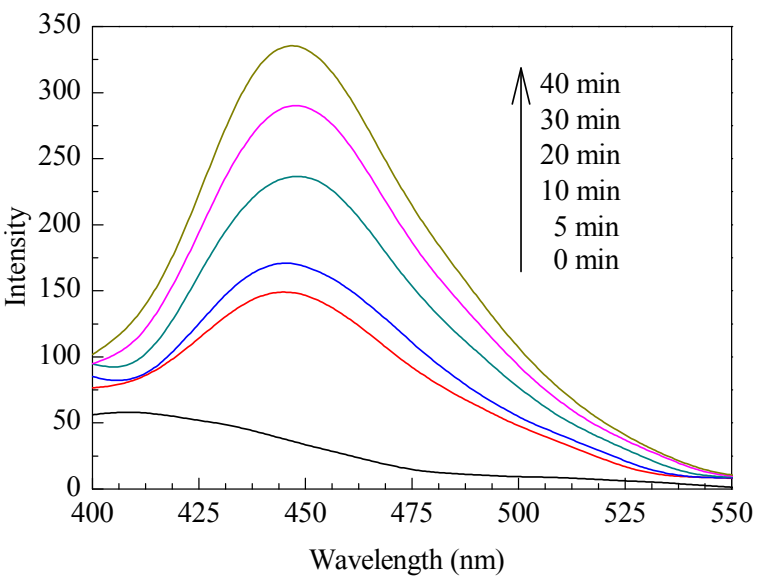

Fig. 11. Photoluminescence spectral change observed during visible light illumination (> $420 \mathrm{~nm}$ ) of $\mathrm{N}$-graphene/CdS HSNs in coumarin solution (excitation at $332 \mathrm{~nm}$ ).

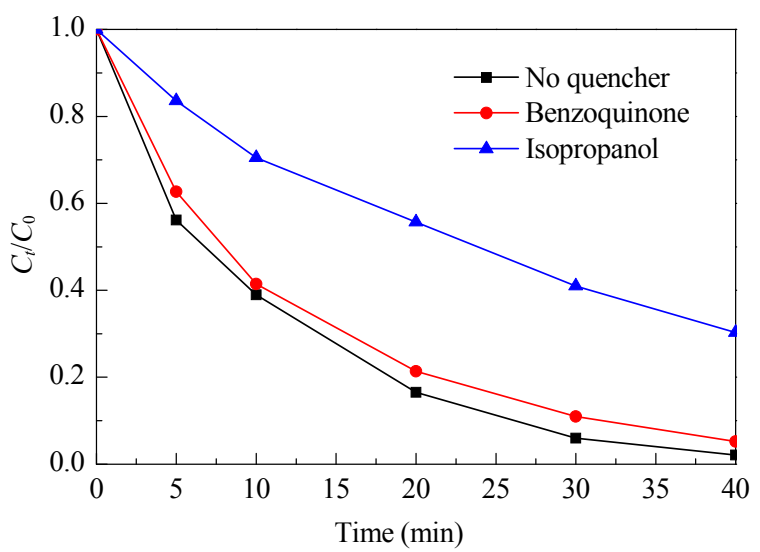

Fig. 12. Photocatalytic activity of N-graphene/CdS HSNs photocatalysts with different quenchers.

mechanism is proposed as illustrated in Fig. 13. Under visible light irradiation, electrons $\left(\mathrm{e}^{-}\right)$are excited from the valence bands of the CdS hollow spheres to their conduction bands, thereby forming electron-hole pairs. $\mathrm{N}$-graphene introduced to the CdS hollow spheres serves as an electron collector and transporter. The resulting efficient charge separation increases the lifetime of the charge carriers and enhances the efficiency of the interfacial charge transferred from the CdS hollow spheres to the N-graphene, which leads to higher photocatalytic activity. Meanwhile, the generated conduction

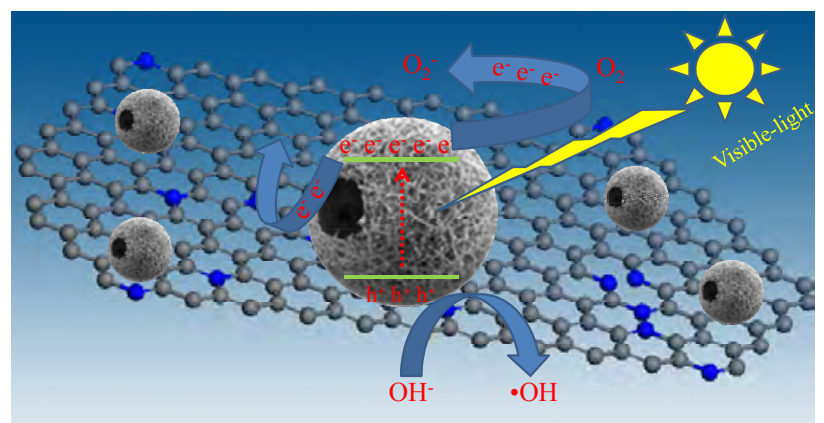

Fig. 13. Schematic diagram showing energy band structure and electron-hole pair separation in N-graphene/CdS HSNs. 
band electrons $\left(\mathrm{e}^{-}\right)$probably react with dissolved oxygen molecules to yield superoxide radical ions $\left(\cdot \mathrm{O}_{2}^{-}\right)$, which on protonation generate hydroperoxy radicals $\left(\cdot \mathrm{HO}_{2}\right)$, producing hydroxyl radical, which was a strong oxidizing agent to decompose organic dye [47]

\section{Conclusions}

We have successfully synthesized N-graphene/CdS HSNs via a simple, template-free one-pot method. The N-graphene/CdS HSNs exhibit enhanced photocatalytic activities for photodegradation of MB and salicylic acid under visible-light irradiation compared with those of pure CdS and GO/CdS HSNs. The enhanced photocatalytic performance can be attributed to the $\mathrm{N}$-graphene, which serves as an electron collector and transporter. Photogenerated electrons were thus able to transfer from the CdS hollow spheres to the N-graphene nanosheets and increase the lifetime of the charge carriers, which improved the photoactivity and stability of the CdS.

\section{References}

[1] Roy P, Berger S, Schmuki P. Angew Chem Int Ed, 2011, 50: 2904

[2] Li X H, Zhang J S, Chen X F, Fischer A, Thomas A, Antonietti M, Wang X C. Chem Mater, 2011, 23: 4344

[3] Zhou T F, Hu J C, Li J L. Appl Catal B, 2011, 110: 221

[4] Podborska A, Gawel B, Pietrzak L, Szymanska I B, Jeszka J K, Lasocha W, Szacilowski K. J Phys Chem C, 2009, 113: 6774

[5] Kumar P, Singh P K, Bhattacharya B. Ionics, 2011, 17: 721

[6] Xiang Q J, Cheng B, Yu J G. Appl Catal B, 2013, 138-139: 299

[7] Tseng H W, Wilker M B, Damrauer N H, Dukovic G.J Am Chem Soc, 2013, 135: 3383

[8] Zhang J, Liu S W, Yu J G, Jaroniec M. J Mater Chem, 2011, 21: 14655

[9] Liu Y, Zhou M J, Hu Y, Qian H S, Chen J F, Hu X. CrystEngComm, 2012, 14: 4507

[10] Qu J Y, Chen H J, Dong S J. Electroanalysis, 2008, 20: 2410

[11] Luo M, Liu Y, Hu J C, Liu H, Li J L. ACS Appl Mater Interfaces, 2012, 4: 1813
[12] Zong X, Yan H J, Wu G P, Ma G J, Wen F Y, Wang L, Li C. J Am Chem Soc, 2008, 130: 7176

[13] Novoselov K S, Geim A K, Morozov S V, Jiang D, Zhang Y, Dubonos S V, Grigorieva I V, Firsov A A. Science, 2004, 306: 666

[14] Zhang Y B, Tan Y W, Stormer H L, Kim P. Nature, 2005, 438: 201

[15] Zhu Y W, Murali S, Cai W W, Li X S, Suk J W, Potts J R, Ruoff R S. Adv Mater, 2010, 22: 3906

[16] Eda G, Chhowalla M. Adv Mater, 2010, 22: 2392

[17] Voloshina E, Dedkov Y. Phys Chem Chem Phys, 2012, 14: 13502

[18] Wei D C, Liu Y Q, Wang Y, Zhang H L, Huang L P, Yu G. Nano Lett, 2009, 9: 1752

[19] He C Y, Li Z S, Cai M L, Cai M, Wang J Q, Tian Z Q, Zhang X, Shen P K. J Mater Chem A, 2013, 1: 1401

[20] Wang H B, Zhang C J, Liu Z H, Wang L, Han P X, Xu H X, Zhang K J, Dong S M, Yao J H, Cui G L.J Mater Chem, 2011, 21: 5430

[21] Palnitkar U A, Kashid R V, More M A, Joag D S, Panchakarla L S, Rao C N R. Appl Phys Lett, 2010, 97: 063102

[22] Wehling T O, Novoselov K S, Morozov S V, Vdovin E E, Katsnelson M I, Geim A K, Lichtenstein A I. Nano Lett, 2008, 8: 173

[23] Zhao Y Y, Zhou Y K, Xiong B, Wang J, Chen X, O' Hayre R, Shao Z P. J Solid State Electrochem, 2013, 17: 1089

[24] Zhang L P, Xia Z H.J Phys Chem C, 2011, 115: 11170

[25] Wu M, Cao C, Jiang J Z. Nanotechnology, 2010, 21: 505202

[26] Deifallah M, McMillan P F, Cora F. J Phys Chem C, 2008, 112: 5447

[27] Wang H B, Maiyalagan T, Wang X. ACS Catal, 2012, 2: 781

[28] Li X L, Wang H L, Robinson J T, Sanchez H, Diankov G, Dai H J. J Am Chem Soc, 2009, 131: 15939

[29] Fan H X, Li Y, Wu D, Ma H M, Mao K X, Fan D W, Du B, Li H, Wei Q. Anal Chim Acta, 2012, 711: 24

[30] Li H B, Lu T, Pan L K, Zhang Y P, Sun Z. J Mater Chem, 2009, 19: 6773

[31] Wen Z H, Wang X C, Mao S, Bo Z, Kim H, Cui S M, Lu G H, Feng X L, Chen J H. Adv Mater, 2012, 24: 5610

[32] Liu Y, Hu J C, Zhou T F, Che R C, Li J L. J Mater Chem, 2011, 21: 16621

[33] Li T T, He Y M, Lin H J, Cai J, Dong L Z, Wang X X, Luo M F, Zhao L H, Yi X D, Weng W Z. Appl Catal B, 2013, 138-139: 95

[34] Bourlinos A B, Gournis D, Petridis D, Szabo T, Szeri A, Dekany I. Langmuir, 2003, 19: 6050

[35] Li X L, Wang H L, Robinson J T, Sanchez H, Diankov G, Dai H J.J Am

\section{Graphical Abstract}

Chin. J. Catal., 2013, 34: 2138-2145 doi: 10.1016/S1872-2067(12)60641-X

\section{Nitrogen-doped graphene/CdS hollow spheres nanocomposite with enhanced photocatalytic performance}

Qian Mi, Daiquan Chen, Juncheng Hu*, Zhengxi Huang*, Jinlin Li*

South-Central University for Nationalities
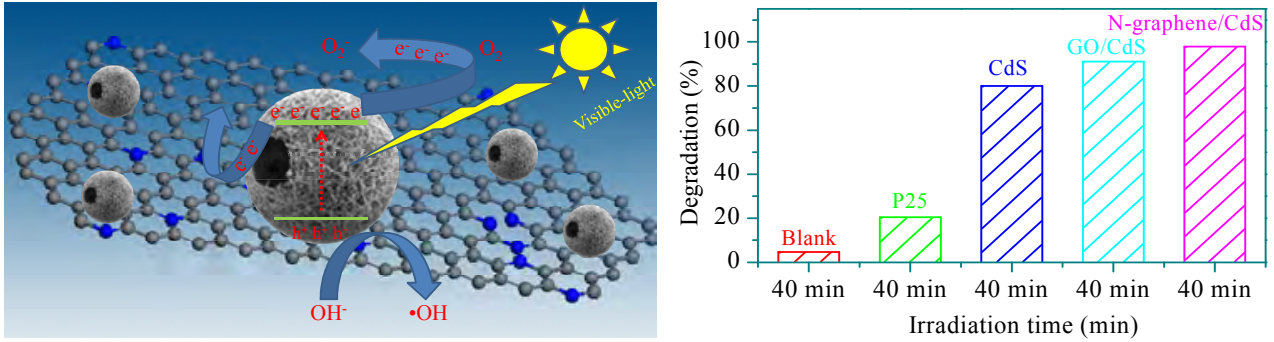

A nitrogen-doped graphene/CdS hollow sphere nanocomposite (HSN) was synthesized by a simple, template-free one-pot method. The $\mathrm{N}$-graphene acted as an electron transfer channel to reduce the recombination of photogenerated electron-holes, which led to dramatically enhanced photoactivity and stability. 
Chem Soc, 2009, 131: 15939

[36] Jia L, Wang D H, Huang Y X, Xu A W, Yu H Q. J Phys Chem C, 2011, 115: 11466

[37] Xu Y X, Bai H, Lu G W, Li C, Shi G Q. J Am Chem Soc, 2008, 130 : 5856

[38] Geng D S, Yang S L, Zhang Y, Yang J L, Liu J, Li R Y, Sham T K, Sun X L, Ye S Y, Knight S. Appl Surf Sci, 2011, 257: 9193

[39] Long D H, Li W, Ling L C, Miyawaki J, Mochida I, Yoon S H. Langmuir, 2010, 26: 16096

[40] Kwon O S, Park S J, Hong J Y, Han A R, Lee J S, Oh J H, Jang J. ACS Nano, 2012, 6: 1486
[41] Sun Y Q, Li C, Shi G Q.J Mater Chem. 2012, 22: 12810

[42] Zhang X Y, Li H P, Cui X L, Lin Y H.J Mater Chem, 2010, 20: 2801

[43] Zhou K F, Zhu Y H, Yang X L, Jiang X, Li C Z. New J Chem, 2011, 35: 353

[44] Zhang H, Zhu Y F. J Phys Chem C, 2010, 114: 5822

[45] Chang H X, Lü X J, Zhang H, Li J H. Electrochem Commun, 2010, 12: 483

[46] Luo M, Liu Y, Hu J C, Li J L, Liu J, Richards R M. Appl Catal B, 2012, 125: 180

[47] Cao T P, Li Y J, Wang C H, Zhang Z Y, Zhang M Y, Shao C L, Li Y C. J Mater Chem, 2011, 21: 6922

\section{氮掺杂石墨烯负载的硫化镉空心球纳米复合材料的光催化性能}

米倩, 陈带全, 胡军成 ${ }^{*}$, 黄正喜 ${ }^{\#}$, 李金林 ${ }^{\$}$

中南民族大学催化材料科学国家民委-教育部重点实验室, 湖北武汉 430074

摘要: 通过无模板法一步合成了一种新型 $\mathrm{N}$ 掺杂石墨烯负载的 $\mathrm{CdS}$ 空心球复合材料. 采用X射线衍射、透射电镜、红外光谱、紫 外-可见光谱、 $\mathrm{N}_{2}$ 吸附-脱附、荧光光谱和X射线光电子能谱等技术对该材料进行了表征, 并在可见光照射下测试了其在降解亚甲 基蓝和水杨酸中的光催化性能. 结果表明, 相对于氧化石墨烯负载硫化镉空心球和单独的硫化镉空心球, 氮掺杂石墨烯负载的硫 化镉空心球具有更高的光催化活性和稳定性. 这是由于氮掺杂的石墨烯能充当优异的电子受体和传输体, 从而抑制了载流子的 复合. 另外发现, 羟基自由基是可见光下降解亚甲基蓝的主要活性物种.

关键词: 氮掺杂石墨烯; 硫化镉; 空心球; 光催化

收稿日期: 2013-06-04. 接受日期: 2013-06-21. 出版日期: 2013-11-20.

*通讯联系人. 电话: (027)67841302; 传真: (027)67842752; 电子信箱: junchenghuhu@hotmail.com

\#通讯联系人. 电话: (027)67842752; 传真: (027)67842752; 电子信箱: zxhuang2005@126.com

\$通讯联系人. 电话: (027)67843016; 传真: (027)67842752; 电子信箱: jinlinli@aliyun.com

基金来源：国家重点基础研究发展计划(2011CB211704); 国家自然科学基金(20803096, 21073238); 湖北省杰出青年基金 (2010CDA082).

本文的英文电子版由Elsevier出版社在ScienceDirect上出版(http://www.sciencedirect.com/science/journal/18722067). 